http://www.jfas.info

\title{
USING PARALLEL COMPUTING IN MODELING AND OPTIMIZATION OF MINERAL RESERVES EXTRACTION SYSTEMS
}

\author{
D. V. Petrov ${ }^{*}$, P. V. Vasiliev, V. M. Mikhelev, V. V. Muromtcev and D. S. Batischev
}

Belgorod State University, Belgorod, Russia

Published online: 15 February 2017

\begin{abstract}
Annotation This article describes algorithm for solving ultimate pit limit problem (UPIT), or a maximum weight closure problem. There are several method for solving this problem. We provide new approach, for solving ultimate pit limit problem using precedence model. Block model of open pit can be easily represented as an oriented graph. Then to solve ultimate pit limit problem it is required to find such a sub graph in a graph whose sum of weights will be maximal. One of the possible solutions of this problem is using genetic algorithms. We use a parallel genetic algorithm for accelerating of computational process. In this version of algorithm fitness function of each individual calculating in different thread. It allows reducing running time of algorithm. Details of implementation parallel genetic algorithm for searching open pit limits are provided. Comparison with other methods and results of computational experiments provided.
\end{abstract}

Keywords: open pit limits, genetics algorithms, high-performance computing.

\section{INTRODUCTION}

There are several classes of tasks in open pit optimization problem. It determination depend on the accounting in them various factors (time, production limitations, etc). At this article, we consider an algorithm solving ultimate pit limit problem (UPIT), or a maximum weight closure problem. It is simplified version of the production-scheduling problem that details the shape of the final pit, or part of the mine design.

\footnotetext{
Author Correspondence, e-mail: petrov@bsu.edu.ru

doi: http://dx.doi.org/10.4314/jfas.v9i1s.747
} 
It takes as given an undiscounted value for each block in a deposit; this value is based on a selling price, an estimated quantity of ore and waste contained in each block, the corresponding costs associated with block extraction, and, if applicable, processing. The model then determines the pit boundary to maximize undiscounted ore value. The ultimate pit limit problem ignores the dimension of time, and, hence, the time value of money. Omissions due to the lack of a temporal aspect include operational resource constraints, ore blending constraints, and stockpiling considerations. The problem also assumes that the cutoff grade, i.e., the grade that separates ore from waste, is fixed. The assumption is that blocks above a threshold ratio of ore to total tonnage are sent to a processing plant, whereupon value (based on selling price less extraction and processing costs) is derived from the block, while those whose ratio falls below the threshold are sent to the dump, whereupon a cost is incurred from having extracted the block.

Results of testing wells and mine workings are used as an initial data for the analysis of ore deposits. On this basis, computer methods for constructing polygonal, triangulation, and interpolation models of ore bodies make it possible to obtain detailed economic block models of deposits [1,2]. It is obvious that than larger and more accurate the block model of the deposit, than more computationally complex is the calculation process. In this regard, using of modern high-performance computing systems is relevant in this area.

There are a several different algorithms for solving ultimate pit limit problem, such as floating cone method, Lech-Grossman algorithm, genetic algorithm, and others [3]. All of them have different advantages and disadvantages. In this article we describe modification of parallel genetic algorithm described in $[4,5]$ by changing principle of representing chromosomes and introducing other genetic operators.

\section{Solving ultimate pit limit problem using precedence model}

A common construct in open pit mining problems is the notion of spatial reference points called blocks. Each block of this model characterized by a number (weight) showing the net profit obtained during its extraction, taking into account percentage of useful elements, cost of production and market price of useful components.

Fig. 1 shows an example of cross section of block model; the bold line indicates the optimal form of the quarry in this section. 


\begin{tabular}{|c|c|c|c|c|c|c|c|c|c|c|c|c|c|c|c|c|c|c|}
\hline-4 & -4 & -4 & -4 & 4 & 8 & 12 & 12 & 0 & -4 & -4 & -4 & -4 & -4 & 4 & 4 & -4 & -4. & 4 \\
\hline & -4 & -4 & -4 & -4 & 0 & 12 & 12 & 8 & -4 & -4 & -4 & 4 & -4 & -4 & -4 & 4 & 4 & \\
\hline & & -4 & 4 & -4 & $\frac{15}{4}$ & 8 & 12 & 12 & 8 & 4 & 4 & 4 & 4 & 4 & -4 & -4 & & \\
\hline & & & -4 & 4 & -4 & (3) & 12 & 12 & 8 & -4 & -4 & 4 & -4 & 4 & -4 & & & \\
\hline & & & & -4 & -4 & -4 & 8 & 82 & 12 & (0) & 4 & 4 & -4 & -4 & -4 & & & \\
\hline & & & & & 4 & -4 & 管 & 12 & 12 & 8 & -4 & -4 & 4 & 4 & & & & \\
\hline & & & & & & 4 & 4 & 8 & 12 & 12 & 0 & -4 & -4 & 4 & & & & \\
\hline
\end{tabular}

Fig.1. An example of the cross section of the block model of the deposit

Dark blocks with a positive weight value are blocks that contain useful elements and are profitable to extract, light blocks with negative weight value are an empty breed, which enterprise only spends money obtaining.

Solving ultimate pit limit problem is to search shell of quarry at the end of life of the mining enterprise. It consists in finding a set of recoverable three-dimensional blocks of ore and rock in order to maximize profit in the presence of precedent limitations related to the stability of the slopes of the sides.

Geometric sequencing constraints ensure that the pit walls are stable and that the equipment can access the areas to be mined.When removing 10 blocks, the angle of slope of the boards for blocks lies in the range from 35 to 45; when removing 6 blocks, the angle of slope of the boards for blocks lies in the range from 45 to 55 (fig. 2). Moving from cubical blocks to blocks in the form of parallelepipeds with different sizes along the $\mathrm{X}, \mathrm{Y}$ and $\mathrm{Z}$ axes, we can achieve a change in the values in the required range of angles. These rules for the sequencing of blocks are interpreted as some approximation of the models of strategic planning.
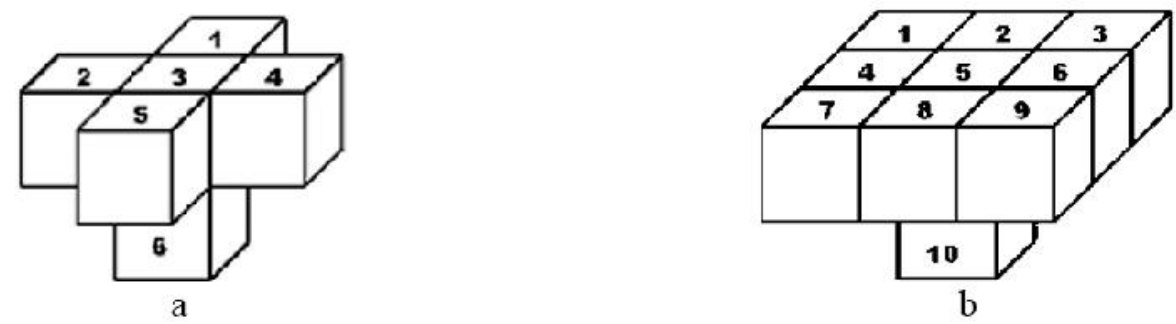

Fig.2. Sequencing rules can be based, for example, on the removal of five blocks above a given block, block 6 (a) or on the removal of nine blocks above a given block, block 10 (b).

Block model shown in Fig. 1 can be easily represented as an oriented graph if we introduce the concept of a precedence constraint. These precedence constraints ensure that blocks immediately affecting a given block's ability to be mined are extracted before the given block is 
extracted.The relationship between block precedences is clearly transitive, i.e., if block a requires block $\mathrm{b}$ to be extracted, and block $\mathrm{b}$ requires block $\mathrm{c}$ to be extracted, then block a also requires block c to be extracted; this transitivity is implied by the original precedences. These sequencing rules can be thought of as approximations in strategic planning models to those used for tactical production scheduling. Fig. 3 shows an example of a precedence graph for the block model shown in Fig. 1.

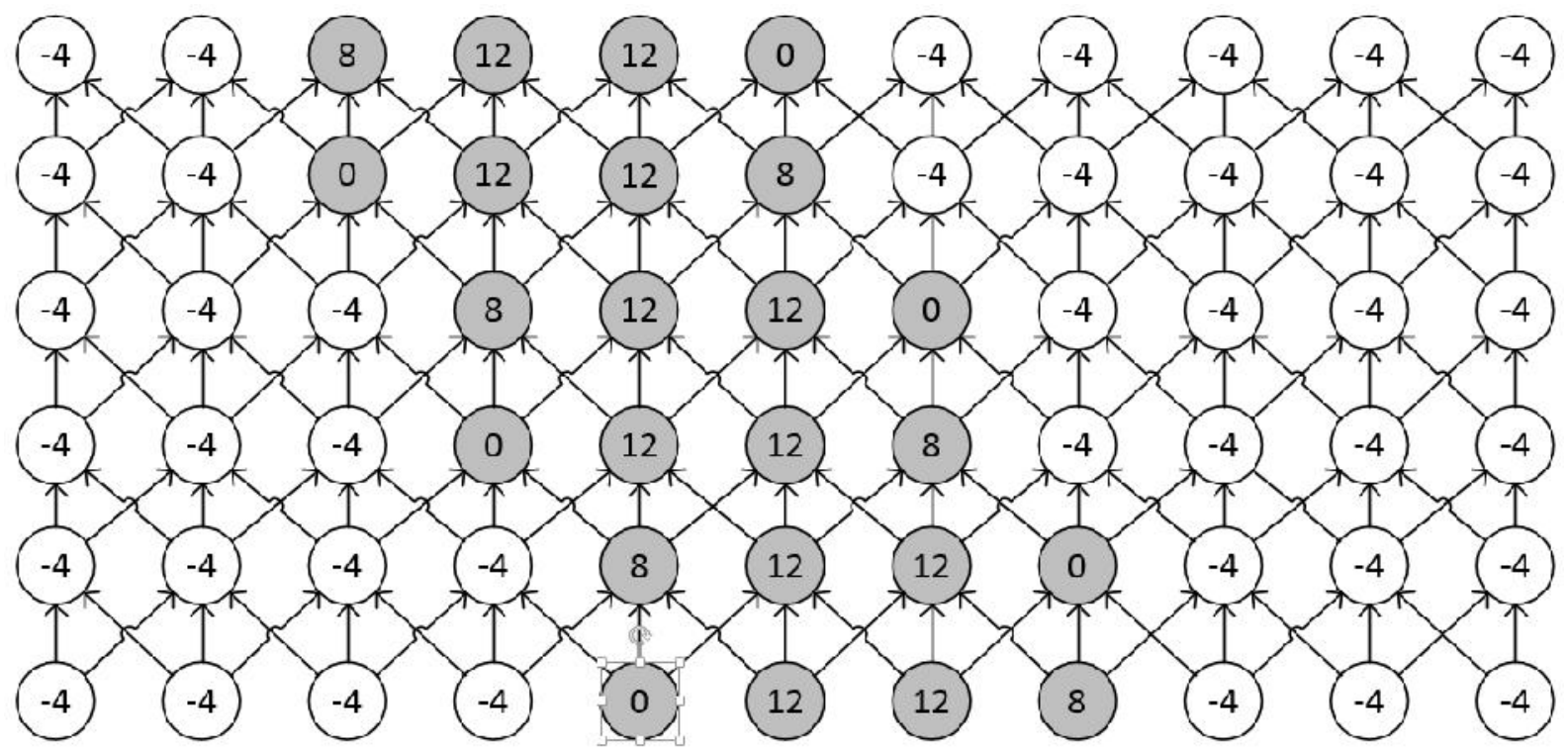

Fig.3. Representing a block model as a precedence graph

When we present an open pit model in this form, to solve ultimate pit limit problem it is required to find such a subgraph in a graph whose sum of weights will be maximal. One of the possible solutions of this problem is using genetic algorithms.

\section{Parallel genetic algorithm}

Genetic algorithms are one of the evolution methods for solving optimization and global search problems. Mutation and natural selection are two driving factors of evolution in nature and they are successfully modeling technical optimization problems and show good results $[6]$.

The main principle of the genetic algorithm is the coding of each solution of the assigned problem by its genotype. In (1) $\mathrm{G}$ is genotype, $\mathrm{g}_{\mathrm{i}}$ is a value of gene.

$$
\mathrm{G}=\left\{\mathrm{g}_{1}, \mathrm{~g}_{2}, \ldots, \mathrm{g}_{\mathrm{n}}\right\}, \mathrm{g}_{\mathrm{i}}, \mathrm{i} \in[1, \mathrm{n}]
$$

In this case, an analogy between the solution and the individual (a living organism) is made. Having selected initial population as a finite set of individuals' genotypes (2), and subsequently applying to them genetic operators (selection, mutation and cross-over), we can achieve improvement (optimization) of the value of the objective function. 


$$
P=\left\{G_{1}, G_{2}, \ldots, G_{m}\right\}
$$

Genetic algorithm solving ultimate open pit limit problem is described in detail in works [4, 5]. However, in above implementation, due to specificity of chromosome presentation format, a significant part of computational resources was spent adjusting the shape of pit boundaries in accordance with predetermined restrictions on the slope angles of pit. Each generated form of open pit had to be checked for correctness and discarded at the selection stage in case it did not fit the given limitations.

In this paper, it is proposed to use a different format for chromosomes representing, which excludes the possibility of forming an open pit of an incorrect form during the process of mutation and crossing. Due to this, it is possible to significantly reduce the amount of computation and reduce the time required for solving the problem.

Calculation of precedence graph is used as an additional stage of processing the deposit model for correctly take into account the restrictions on the angles of slope of the quarries. In the course of this procedure, 3D block model of open pit is transformed into a precedence graph, as described in paragraph 2 of this work.

If $\mathrm{P}_{\mathrm{IxJXK}}$ is a three-dimensional block model, each element of which is characterized by a number (weight) showing the net profit obtained in the course of its production, taking into account percentage of useful elements, cost of production and market value of useful components (3)

$$
\mathrm{p}_{\mathrm{ijk}}, \mathrm{i} \in[1, \mathrm{I}], \mathrm{j} \in[1, \mathrm{~J}], \mathrm{k} \in[1, \mathrm{~K}]
$$

Then, on its basis, taking into account the restrictions on the angles of slope of the sides of the pit, at each point it is possible to construct a weighted oriented precedence graph (4)

$$
\mathrm{G}=\{\mathrm{V}, \mathrm{E}\}
$$

Where $\mathrm{V}$ is the set of vertices. Count of vertices is equal to count of block model elements. Each vertex is characterized by its weight (5)

$$
\mathrm{v}_{\mathrm{q}}=\mathrm{p}_{\mathrm{ijk}}
$$

$\mathrm{E}$ is the set of ordered pairs of vertices $\mathrm{u}, \mathrm{v} \in \mathrm{V}$. Then we can take a subset of vertices (6)

$$
\mathrm{R}=\left\{\mathrm{r}_{1}, . ., \mathrm{r}_{\mathrm{n}}\right\}
$$

For each vertex ri, we can construct a subgraph Qi of graph G such that Qi includes all the vertices associated with the vertex ri recursively until reaching the upper layer. Then union of subgraphs (7) is graph characterizing a particular form of open pit.

$$
\mathrm{D}=\mathrm{Q}_{1} \cup \mathrm{Q}_{2} \cup \ldots \cup \mathrm{Q}_{\mathrm{n}}
$$


In this case, the set $\mathrm{R}$ can be considered a chromosome, because it fully characterizes one individual (one particular form open pit).Iterative application of genetic operators to collection of such individuals (populations) find optimum shape of open pit surface. As a fitness function used function (8).

$$
f(D)=\sum_{i=1}^{m} d_{i}
$$

Where $d_{i}$ is a weight of vertex of graph D. Algorithm stops working when its execution ceases to lead to an improvement in the maximum fitness function value in the population. The onset of this moment is determined by checking the condition (9):

$$
\left|\max _{i=1, N}\left(f\left(D_{i}^{k}\right)\right)-\max _{i=1, N}\left(f\left(D_{i}^{k-1}\right)\right)\right|<\varepsilon
$$

Where $\mathrm{N}$ is a size of the population, $\mathrm{k}$ is an iteration number. This algorithm finds the limiting shape of open pit in a finite number of steps.

We use a parallel genetic algorithm for accelerating of computational process. In this version of algorithm fitness function of each individual calculating in different thread. It allows reducing running time of algorithm.

\section{Computational experiments}

Belgorod State University computational cluster was used as a platform for computational experiment. One cluster node with 2 processors with a frequency of $2.4 \mathrm{GHz}$ and 8 cores in each 16 physical computing cores) was used for computational experiments.

Minelib model newman1 [7] is used as source data for computational experiments. This model consists of 1060 blocks of unknown size. We interpolated model data to a resolution of 100 per 100 per 50 blocks. The total number of blocks in the model thus amounted to 500000 . Visualisation of three dimensional model provided on fig. 4(a). Example of tree-diminutions visualization of open pits' limits provided on fig. 4 (b).

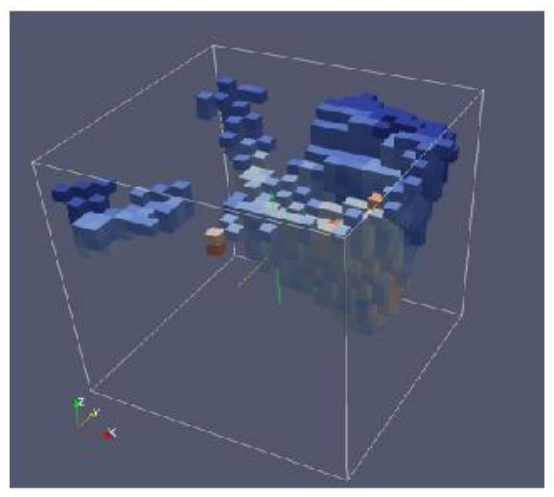

a

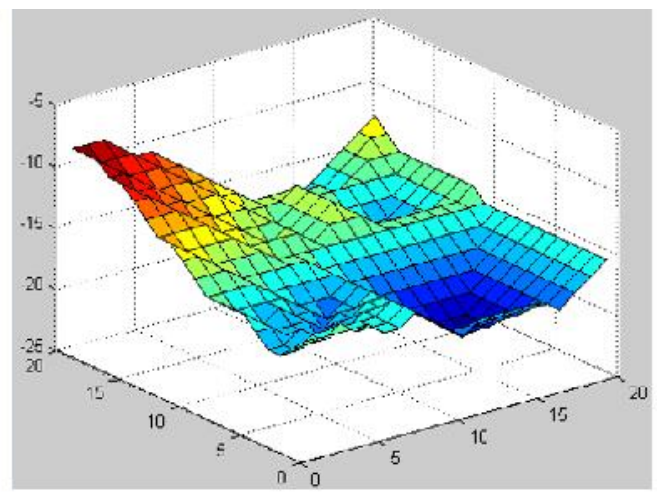

b

Fig.4. (a) Open pit block model (b) Tree-dimensional view of open pit model 
Table 1 shows results of computation for this model by genetic algorithm described in [4,5] and new genetic algorithm with precedent models of open pit.

Table 1. Results of computational experiments

\begin{tabular}{llccl}
\hline Threads Computation & $\begin{array}{l}\text { time, Computation } \\
\text { sec., genetic } \\
\text { rithm }\end{array}$ & $\begin{array}{l}\text { time, } \\
\text { algo- }\end{array}$ & $\begin{array}{l}\text { seceleration, new genetic algo- } \\
\text { rithm }\end{array}$ & $\begin{array}{l}\text { Acceleration, new } \\
\text { genetic } \\
\text { rithm }\end{array}$ \\
\hline 1 & 610.42 & 438.23 & 1.00 & 1.00 \\
2 & 317.61 & 226.00 & 1.92 & 1.94 \\
4 & 158.74 & 111.96 & 3.85 & 3.91 \\
6 & 107.37 & 75.08 & 5.69 & 5.84 \\
8 & 81.53 & 55.53 & 7.49 & 7.89 \\
10 & 63.81 & 44.81 & 9.57 & 9.78 \\
12 & 55.73 & 38.01 & 10.95 & 11.53 \\
14 & 49.04 & 32.21 & 12.45 & 13.61 \\
16 & 42.80 & 28.73 & 14.26 & 15.26 \\
\hline
\end{tabular}

Fig. 5 shows dependence between execution time and number of used cores, Fig. 6 shows dependence between acceleration and number of used cores.

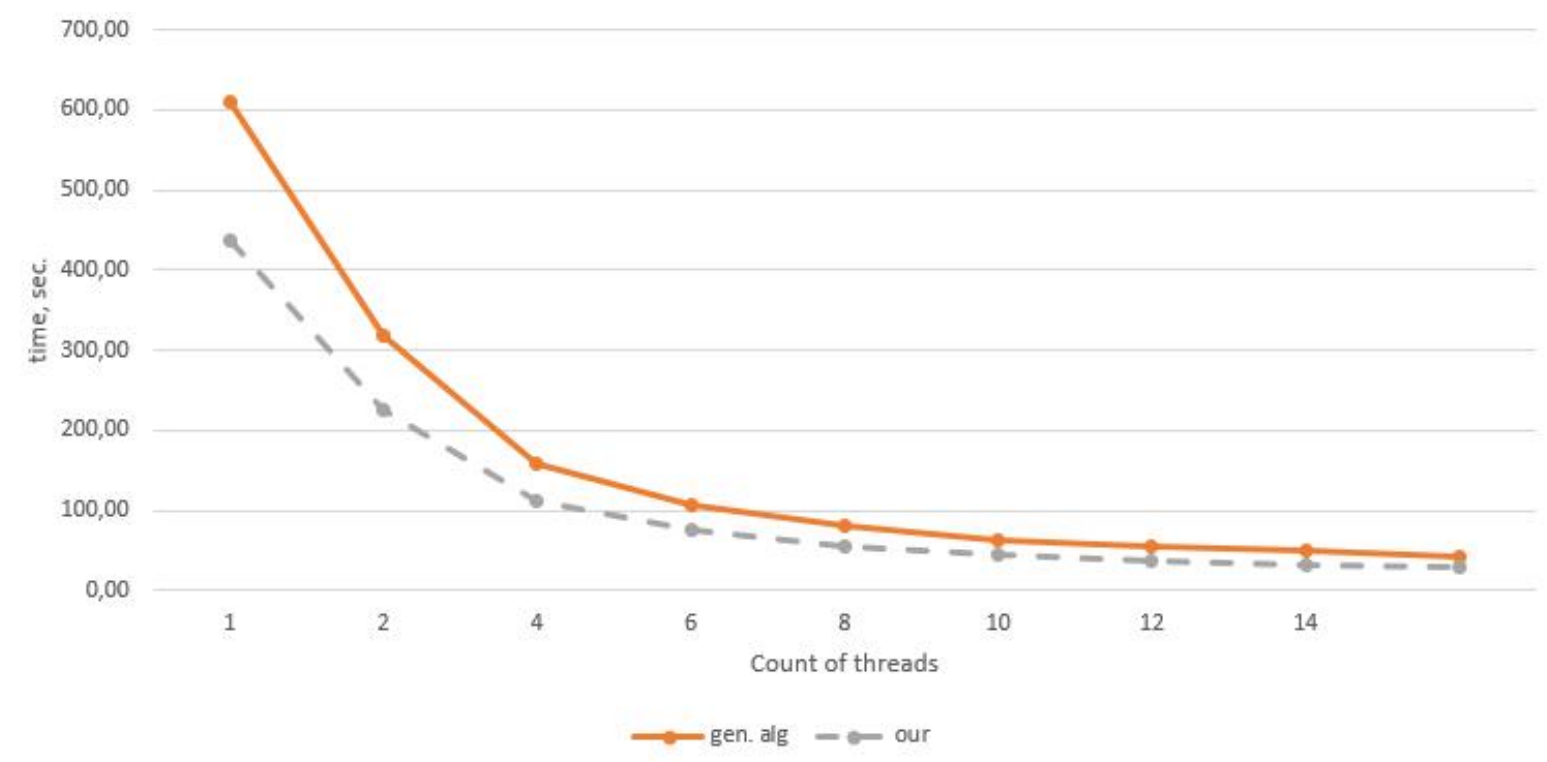

Fig.5. Dependence between execution time and number of used cores 


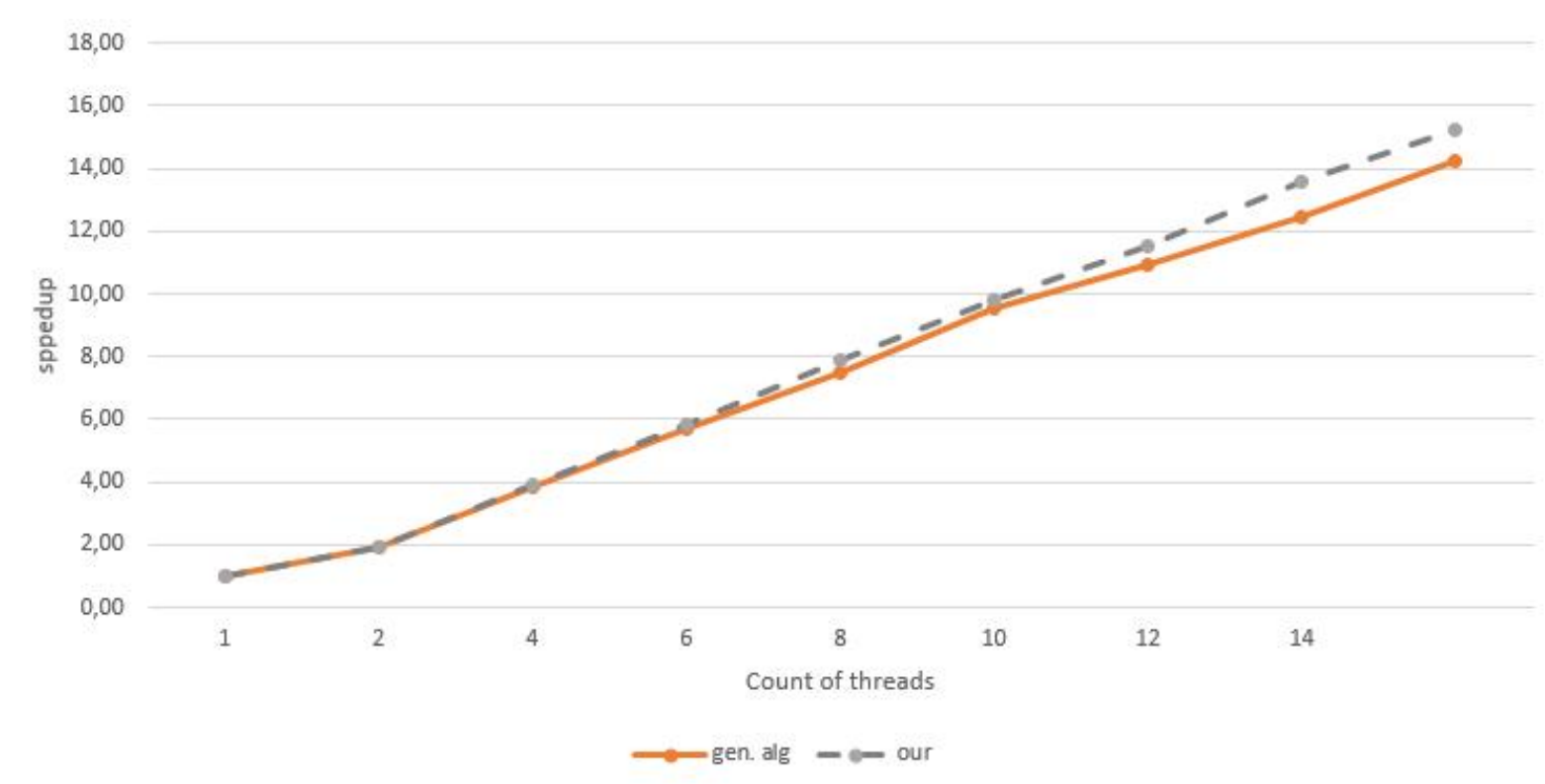

Fig.6. Dependence between acceleration and number of used cores

\section{SUMMARY}

Results of computational experiments hadshowedhigh promiseof the proposed methodto perform calculationson precedent models of open pits. Using parallel genetic algorithm based on precedence model worked faster than simple genetic algorithm. This allows process largescale models in less time.

\section{CONCLUSION}

We proposed a new framework to solve ultimate open pit limits problem. The main advantage of this method is a providinga new principle ofoptimization problempits, which let to work directly with thethree-dimensionalmodel of the pit. It greatly improves the adequacy ofthe modelobtained. In addition,the flexibilityto scalecomputing processcanshorten thecalculationmodel almostlinearlywith the number ofnodes.

\section{REFERENCES}

1.Whittle D.J., Vassiliev P.V. 1997. Construction Economic Ore Body Models for Open Pit Optimization. Moscow. S.N.2nd Regional APCOM 97 SYMPOSIUM.8: 511-514

2.P.V. Vasil'ev, V.M. Mikhelev, D.V. Petrov.2015.Otsenkavychislitel'noyslozhnostialgoritmovoptimizatsiigranitskar'erov $\mathrm{v}$ sistemenedropol'zovaniya [Computational complexity for open pit optimization algorithms in mining mineral reserves]. NauchnyevedomostiBelGU, SeriyaEkonomika. Informatika [Belgorod State University Scientific Bulletin. Ser. Economics. Information technologies]. 8(34/1): 205(in Russian) 
3.Vasil'ev P.V., Buyanov E.V.2000. O metodikesovmestnoyrabotyprogramm MapInfo iGeoblockpookonturivaniyuipodschetuzapasovrudnykhmestorozhdeniy [On the method of joint work programs MapInfo and Geoblock for contouring and reserves estimation of ore deposits]. InformatsionnyyByulle-ten' GIS Assotsiatsii [Newsletter GIS Association].2: 32-33(in Russian)

4.Petrov D.V., Mikhelev V.M.2014.Modelirovaniekar'erovrudnykhmestorozhdeniynavysokoproizvoditel'nykhgibridnykhvychislitel'nykhsistemakh [Modeling quarries ore deposits in the hybrid high-performance computing systems]. VestnikYuzhnoUral'skogogosudarstvennogouniversiteta. Seriya: Vychislitel'nayamatematikaiinformatika. [Bulletin of South Ural State University. Series: Computational Mathematics and Informatics]. 3(3): 124-129 (in Russian)

5.Mihelev V.M., Vasilev P.V., Petrov D.V.2013. Superkomp'jutery, kaksredstvamodelirovanijagranichnyhkonturovkar'erovrudnyhmestorozhdenij [Supercomputers as a means of modeling the boundary contours of ore deposits quarries], Voprosyradiojelektroniki. Serija "Jelektronnajavychislitel'najatehnika (JeVT)" [Questions electronics. A series of "Electronic computers"]. Moscow.1: 5-10(in Russian)

6.Rutkovskaja D., Pilin'skij M., Rutkovskij L. 2007. Nejronnyeseti, geneticheskie algoritmyinechetkiesistemy [Neural networks, genetic algorithms and fuzzy systems], GorjachajaLinija Telekom [Hot Telecom Line] (in Russian)

7.Espinoza D, Goycoolea M, Moreno E, Newman A. 2013. Minelib 2011: A library of open pit production scheduling problems. Ann. Oper. Res. 206(1): 93-114.

8.Elahizeyni E., Ka-kaie R., Yousefi A.2011. A new algorithm for optimum open pit design: Floating cone method III. 2. Journal of Mining \& Environment. 2: 118-125.

9.Khalokakaie, R. 2006. "Optimumopenpitdesign withmodifiedmovingconeIImethods",Journalof engineeringin Tehran university. 4(3): 297-307 (in Persian).

10.Carlson T.R., Erickson J.D., O’Brain D.T., Pana M.T. 1966; Computer tech-niques in mine planning. Mining Engineering. 18(5): 53-56

\section{How to cite this article:}

Petrov D V, Vasiliev P V, Mikhelev V M, Muromtcev V V, Batischev D S. Using parallel computing in modeling and optimization of mineral reserves extraction systems. J. Fundam. Appl. Sci., 2017, 9(1S), 939-947. 